Paidéia, 2006, 16(33), 193-203

\title{
MUDANÇAS GERADAS PELA INTERNET NO COTIDIANO ESCOLAR: AS REAÇÕES DOS PROFESSORES ${ }^{1}$
}

\author{
Rosane de Albuquerque dos Santos Abreu ${ }^{2}$ \\ Colégio de Aplicação - Universidade Federal Rio de Janeiro \\ Ana Maria Nicolaci-da-Costa \\ Pontifícia Universidade Católica doRio de Janeiro
}

\begin{abstract}
Resumo: A Internet gerou novas formas de produção, divulgação e armazenamento de conhecimentos e informações, as quais têm provocado profundas mudanças nos processos pedagógicos tradicionais. A análise de 20 entrevistas realizadas com professores do ensino Fundamental e Médio de escolas particulares do Rio de Janeiro foi reveladora. Suas respostas, reações, comentários e atitudes indicam que tais mudanças os têm atingido profundamente e feito enfrentar dolorosos conflitos internos. Mesmo assim, eles estão conscientes de que precisam aprender a lidar com alguns dos novos fenômenos produzidos pela Internet, principalmente com o excesso, a superficialidade e a renovação constante de informações. Por isso mesmo estão: revendo os conceitos de informação e conhecimento; reformulando práticas pedagógicas tradicionalmente usadas na pesquisa escolar; tentando se adaptar às transformações na tradicional relação professor-aluno na qual antes eram poderosos e privilegiados transmissores de conhecimento; finalmente, alterando a própria concepção do que significa ser professor hoje.
\end{abstract}

Palavras-chave: Internet; informação; conhecimento; professores; conflitos internos.

\section{CHANGES PRODUCED BY THE INTERNET IN SCHOOL LIFE: TEACHERS' REACTIONS}

Abstract: New forms of production, release and information storage and knowledge have brought deep changes in traditional educational processes. The analysis of 20 interviews carried out with private elementary and high school teachers in the city of Rio de Janeiro was revealing. Their answers, reactions, comments and attitudes indicate that such changes have had a lot of impact and made them experience painful inner conflicts. Nevertheless they are conscious that they need to learn how to deal with some of the new phenomena generated by the Internet, mainly with the excess, the superficiality and constant information update. For this reason they are: reviewing the concepts of information and knowledge; reformulating educational practices traditionally used in school research; trying to adapt themselves to the transformations in the traditional teacher-student relationship in which they once were the powerful and privileged transmitters of knowledge; finally, altering their conception of what means to be a teacher today.

Key words: Internet; information; knowledge; teachers; inner conflicts.

\section{Introdução}

Iniciada em décadas anteriores (final da de 1960 e início da de 1970), a chamada Revolução Digital se intensificou a partir da comercialização da Internet em meados dos anos 1990, provocando significativas mudanças nas mais diversas atividades humanas. Incrementou as alterações iniciadas pela difusão dos

\footnotetext{
${ }^{1}$ Recebido em 11/09/06 e aceito para publicação em 13/11/06.

${ }^{2}$ Endereço para correspondência: Rosane de Albuquerque dos Santos Abreu, Rua: Januário José Pinto de Oliveira, 75 - Recreio, CEP: 22785-430, Rio de Janeiro - RJ, E-mail: rosane.abreu@terra.com.br
}

computadores nos processos produtivos, no mercado de trabalho, nas empresas e organizações, na produção cultural, nas relações sociais. Os impactos da Internet foram tão grandes que a maior parte das atividades humanas atualmente dela não pode prescindir (Castells, 1999, Cébrian, 1999; Dertouzos, 1997; Lévy, 1999; Lojkine, 1995; Negroponte, 1995).

$\mathrm{O}$ advento da Internet também gerou fortes impactos em diversas áreas de atuação profissional. Uma delas é a da Educação. As novas formas de produção, divulgação e armazenamento de conhecimentos e informações tornadas possíveis pela 
interconexão dos computadores mundiais têm provocado profundas rupturas nos processos pedagógicos tradicionais. A respeito dos novos rumos da educação, Lévy (1999) diz:

"A grande questão da cibercultura (...) é a transição de uma educação e uma formação estritamente institucionalizadas (a escola, a universidade) para uma situação de troca generalizada dos saberes, o ensino da sociedade por ela mesma, do reconhecimento autogerenciado, móvel e contextual das competências." (Lévy, 1999 p. 172)

Cebrián (1999) também fala da "sala de aula sem muros", produzida pelos atuais meios de comunicação que "derrubam as fronteiras geográficas do saber, unificando as experiências das pessoas e universalizando os seus mitos" (Cebrián, 1999 p. 120). Para ele, uma das conseqüências da experiência com os meios de comunicação nos dias atuais é a de que todos podem se tornar autodidatas. Isso porque, ao se conectar à Internet, qualquer pessoa tem como buscar sozinha a informação/conhecimento que deseja ou de que necessita. E também, divulgar idéias e teorias deixando-as ao alcance de muitos para críticas e contribuições. Pode, ainda, discutir temas de seu interesse em comunidades virtuais, ao mesmo tempo em que recebe orientação personalizada de um especialista sobre o assunto que desejar. Essas e outras novas formas, fáceis e ágeis, de busca e elaboração do conhecimento, como não poderia deixar de acontecer, vêm tendo várias conseqüências para os processos educativos levados a cabo nas instituições de ensino.

Entre os agentes do processo educativo que têm sido profundamente atingidos pelas mudanças desencadeadas pela Internet estão os professores. Além de se sentirem impelidos a conhecer uma nova fonte de informação - a Internet -, estes (principalmente aqueles que trabalham com as camadas mais favorecidas da sociedade) sofrem pressões dos alunos, dos pais e da própria escola para absorver a Internet em sua prática cotidiana. Essas e outras exigências atuais estão impulsionando os professores a reverem suas práticas e concepções de ensino. Segundo Lévy (1999):

\begin{abstract}
“(...) a principal função do professor não pode mais ser uma difusão dos conhecimentos, que agora é feita de forma mais eficaz por outros meios. Sua competência deve deslocar-se no sentido de incentivar a aprendizagem e o pensamento. O professor torna-se um animador da inteligência coletiva dos grupos que estão a seu encargo." (Lévy, 1999, p. 170)
\end{abstract}

Para quem historicamente foi responsável por apresentar aos alunos o conhecimento, tal processo de mudança não é simples. Exige rupturas, reconstruções e re-aprendizagens. Exige, também, disposição para enfrentar novos desafios e disponibilidade para se abrir ao desconhecido, abandonando práticas já testadas e concepções estabelecidas. Segue-se uma breve discussão da literatura brasileira sobre esses desafios.

Incorporando a Internet ao cotidiano: revisão da literatura brasileira

Provavelmente por conta do fato de ser tudo muito novo, a literatura sobre os usos da Internet na educação brasileira ainda é confusa e difícil de mapear. Muitos dos trabalhos publicados tentam oferecer subsídios teóricos, técnicos e metodológicos aos professores com vistas à utilização da Internet como ambiente de ensino-aprendizagem (Lucena \& Fuks, 2000; Magdalena \& Costa, 2003; Ramal, 2002). Esses trabalhos têm pelo menos dois pontos em comum: (a) propõem que o professor enfrente o desafio de fazer uso dos novos ambientes, ferramentas, metodologias e técnicas, oferecidas pela Internet, no desenvolvimento dos conteúdos escolares; e, (b) visualizam um novo papel para os professores. Por trás deles, pode-se ainda detectar a intenção dos autores de ajudar os docentes na revisão de suas concepções, de sua ação, de seu papel.

Um outro grupo de trabalhos mostra de que maneira os professores estão, eles próprios, fazendo uso dos recursos que a rede disponibiliza (Boettcher, 2005; Suguri, Matos, Castro, Castro, Jung \& Rusten, 2002; Araújo, Battaiola \& Goyos, 2001). Estes são, geralmente, relatos de experiências pessoais ou resultados de pesquisas que investigam a aplicação da Internet como recurso didático.

Finalmente, um terceiro grupo de trabalhos vem começando a marcar presença na literatura em ques- 
tão; ele é composto pelos trabalhos que analisam as reações dos professores (as ansiedades, os medos, as preocupações, as satisfações.) ao fazer uso de recursos da Internet. Muitas vezes, essas reações são observadas a partir de experiências vividas em cursos de formação e/ou aperfeiçoamento. Um bom exemplo é o trabalho de Maçada, Sato e Maraschin (2001), que apresenta um relato do processo de atualização de professores de matemática para a utilização de recursos da Internet (chat, ICQ, e-mail, lista de discussão). Seus resultados permitem identificar que os professores vivenciam um confronto entre o "velho" regime cognitivo escolar de recepção de conhecimentos prontos e o "novo" regime cognitivo da busca de conhecimentos e descobertas. Revelam, também, sentimentos de desconforto (ansiedade) e de insegurança dos professores nos primeiros contatos com a tecnologia. A investigação das repercussões dessa experiência na prática docente cotidiana, no entanto, foge ao escopo desse estudo.

Já Candeias (1998) apresenta uma pesquisa realizada com dois grupos de professores em um programa de capacitação. Neste programa, um grupo teve contato sistemático com as novas tecnologias (incluindo a Internet) e o outro não. Os resultados obtidos levam Candeias a afirmar que a presença das novas tecnologias na educação não parece ter alterado significativamente as práticas pedagógicas dos professores investigados, mesmo daqueles que as usaram sistematicamente. Este estudo traz importantes contribuições a respeito das representações que os professores têm do trabalho docente e do papel das novas tecnologias na prática pedagógica, mas, tal como o de Maçada e cols (2001), ele também não tinha como objetivo investigar os impactos pessoais para os professores da introdução da Internet no ambiente pedagógico.

Além dos conflitos cognitivos identificados por Maçada e cols (2001), a literatura psicológica mostra que sentimentos contraditórios e conflitos internos são inevitavelmente gerados por processos radicais de mudança (Nicolaci-da-Costa, 1987, 2002). Esses aspectos afetivos do desafio com o qual os educadores estão sendo confrontados não vêm, contudo, se destacando como objeto de estudo na literatura sobre os usos da Internet na educação brasileira. Seja porque é tudo muito recente, seja porque os autores que se dedicam ao estudo da penetração da Internet na educação muitas vezes provêm de áreas distantes da Psicologia, ou mesmo das Ciências Humanas, o fato é que ainda se sabe muito pouco sobre os impactos que a penetração social e educacional da Internet vem gerando no cotidiano dos professores, neles mesmos como profissionais e como pessoas.

Esta é exatamente a contribuição que este trabalho pretende dar, ao dar voz a professores do ensino fundamental e médio, visando analisar seus depoimentos, e verificar como as novidades implementadas pela Internet nos processos de produção, divulgação e armazenamento das informações e conhecimentos estão afetando suas práticas docentes e seus próprios modos de ser.

\section{Método}

Participaram da pesquisa 20 professores que lecionam diferentes matérias (exceto Informática ou Informática Educativa) na $8^{\mathrm{a}}$ série do ensino fundamental e no ensino médio, em escolas particulares da cidade do Rio de Janeiro. Desses vinte professores, 12 são mulheres e 8 homens, com idades variando entre 33 e 53 anos (idade média de 41 anos), e com 3 a 35 anos de magistério. A maioria (16 participantes) tinha mais de 10 anos de experiência profissional e a média de tempo de magistério correspondia a cerca de 18 anos, o que mostra que o grupo era composto por profissionais experientes.

Como usuários de informática, os participantes tinham o seguinte perfil: todos usavam computadores há mais de 5 anos, alguns, no entanto, há 17 anos (a média de tempo de uso era 11 anos). Apenas 2 participantes haviam começado a usar o computador juntamente com a Internet. Os demais foram, primeiramente, usuários de computadores.

Quanto à Internet, 16 professores eram seus usuários há mais de 6 anos, sendo que 2 deles haviam começado a fazer uso da Rede antes dela se tornar comercial. Os outros eram usuários há mais de 3 anos. Quase todos acessavam a rede todos os dias e a ela ficavam conectados por pelo menos 1 hora diariamente. Usavam-na por mais horas nos finais de semana. Todos tinham conexão à Internet em casa, o que levava a maioria a se conectar de sua própria 
residência. O grupo de participantes tinha, portanto, bastante familiaridade com a rede mundial de computadores.

A entrevista individual foi o instrumento usado para a coleta de dados. Os próprios entrevistados escolheram os locais e os horários para os encontros, que duraram cerca de uma hora. Na entrevista, que mais se assemelhava a um bate-papo, buscou-se criar um clima descontraído e informal para que os participantes se sentissem à vontade e livres para revelar seus sentimentos, pensamentos, dificuldades e conflitos. Com o seu consentimento, as entrevistas foram gravadas e depois integralmente transcritas.

Utilizou-se um roteiro de entrevista, previamente elaborado ( Nicolaci-da-Costa, 1994 e no prelo) composto por perguntas fechadas (respostas objetivas ou simples "sim" / "não") e abertas (que comportam qualquer tipo de resposta), sendo que as questões fechadas visavam coletar dados objetivos ou fazer a ponte entre um tópico e outro. Já as questões abertas (a grande maioria) se destinavam a permitir a explanação livre dos participantes a respeito dos diversos tópicos que lhes eram colocados; eram pontos básicos, organizados em forma de itens, a serem abordados e aprofundados quando necessário, estando organizado em quatro blocos: 1- identificação do sujeito (idade, formação, disciplina e séries que leciona, tempo de magistério e local de trabalho); 2- caracterização do sujeito como usuário da Internet (motivos para a conexão, tempo e freqüência de acesso, formas de uso e opiniões sobre a Internet); 3-visão e sentimentos dos entrevistados sobre o uso da Internet na educação (vantagens e desvantagens da Internet para a educação, efeitos de seu uso na sala de aula, sua aplicação ao processo pedagógico); e 4- visão dos participantes a respeito das transformações que a rede está gerando nos processos de divulgação, armazenamento e produção de conhecimentos e informações.

\section{Análise dos Dados}

Os dados coletados foram analisados por meio das técnicas da análise do discurso, tal como propostas por Nicolaci-da-Costa (1994 e no prelo). Após sua transcrição, as entrevistas foram lidas cuidadosamente e a seguir agrupadas as falas dos participantes segundo os tópicos do roteiro. Realizou-se, então, uma comparação das respostas dadas pelos diferentes participantes a cada um dos itens do roteiro (análise inter-participantes). A partir desse procedimento, foram identificados pontos recorrentes em suas respostas, os quais passaram a ser considerados categorias de análise para leituras subseqüentes. Em uma etapa posterior, procedeu-se à leitura e análise do discurso de cada sujeito (análise intra-participantes), procurando identificar possíveis contradições e conflitos individuais. Desta leitura, foram levantadas outras categorias que se juntaram àquelas anteriormente mencionadas.

\section{Resultados}

Os principais resultados que emergiram dos depoimentos dos próprios entrevistados (lembrando que não se partiu de categorias pré-estabelecidas) são apresentados a seguir, sendo que foram dados nomes fictícios a todos os participantes.

\section{Informação e conhecimento: dois conceitos em revisão}

As experiências na Internet parecem instigar os entrevistados a uma revisão do que entendem por informação e conhecimento. Um indício disso foi detectado em suas respostas à questão sobre o que entendem por informação e conhecimento. Vários entrevistados tiveram reações diferentes, mas todas sugeriam que não tinham uma resposta pronta. Alguns fizeram um breve silêncio, como se estivessem refletindo a respeito dos conceitos e buscando as palavras para responder. Outros teceram comentários, tais como: "que pergunta difícil", "é complicado" ou "nossa, como vou responder?" Outros, ainda, não responderam no momento em que lhes foi feita a pergunta e, sim, no decorrer da entrevista. Poucos foram os que deram resposta imediata. Tal conjunto de reações fornece importantes indícios de que os significados destas palavras estão sendo revistos e reconstruídos pelos professores entrevistados.

Para a maioria deles, conhecimento é um processo elaborado, um "processo de digestão", que exige das pessoas "estabelecimento de relações", "reflexão", “introspecção", "processamento", "discernimento". Não é um processo simples, nem rápido, ele necessita de tempo, "requer que você seja capaz de parar um pouco, dar a volta", como explica Paulo Lima. O conhecimento demanda, ainda, segun- 
do vários participantes da pesquisa, uma aplicação, uma experiência, uma produção. Já informação, na visão de todos, é exatamente o inverso. Veja-se a título de exemplo, como Felipe Peixoto define esses dois conceitos:

\begin{abstract}
A informação, eu não sei, é um conceito dificil [risos]. A informação é algo que vem muito rapidamente, que a gente absorve, recebe e não processa ou processa. O conhecimento é parte desse processar. Você lida com a informação, você processa aquilo e faz relação com outras coisas. Ai você constrói o conhecimento. ${ }^{1}$
\end{abstract}

Tais depoimentos, entre muitos análogos, mostram que os entrevistados acham que a construção do conhecimento parte da informação, mas que esta não necessariamente se transforma em conhecimento. Na realidade, para os entrevistados, conhecimento é a informação trabalhada, elaborada e aplicada. Já a informação é superficial, é algo que vem rapidamente, é como um flash.

As diferenças que os entrevistados fazem entre esses dois conceitos ficam ainda mais evidentes quando eles comentam o excesso de dados provenientes do intenso fluxo das informações que circulam no espaço virtual. Seus depoimentos mostram que eles se sentem confusos e preocupados, conforme mostra a fala de Aloísio Santos.

Essa quantidade, essa facilidade enorme de informação, faz com que você entre em um registro, uma velocidade que não te permite nenhum tipo de introspecção sobre aquilo que você está lendo, nenhum tipo de relação. É uma coisa muito superficial, a tela mesmo está se atualizando a cada 5 minutos. O jornal, pelo menos, é de um dia para o outro, mas naqueles portais a informação muda de 2 em 2 minutos.

Já Ivone Machado pondera que "o cérebro da gente é fantástico, mas ele precisa de um tempo para que as coisas aconteçam”. Ou seja, para Aloísio, Ivone e para muitos outros entrevistados, como decorrência do excesso e da renovação rápida das informações, estas tendem a ser e permanecer superficiais. Não há tempo para aprofundamento, para a

\footnotetext{
${ }^{1}$ As falas dos entrevistados foram transcritas literalmente, sem qualquer tipo de edição. São aqui apresentadas da mesma forma.
}

digestão dos dados absorvidos, nem tampouco para a fixação dos mesmos.

O impacto do excesso e da superficialidade das informações parece ter sido grande para vários entrevistados. Muitos revelam seu mal-estar abertamente.

Sônia Cavalcante, por exemplo, demonstra se sentir angustiada frente à quantidade de informações à sua disposição e à necessidade de estar o tempo todo fazendo escolhas.

Hoje em dia você acaba se tomando, assim, por uma grande angústia. Você sabe que muita coisa está à sua disposição e você não vai ter tempo, nem chance de checar aquilo tudo ali.

Ivete de Souza, por sua vez, fala que, diante de "um mundo de informações", a única saída é tratar de forma superficial os dados que chegam.

Você abre uma página, um portal, e você tem flashes de informação. E a pessoa, tão angustiada por ter que dominar tudo, que é humanamente impossível, fica pegando só flashes. São noticiários, não tem a leitura mais aprofundada.

Esse tratamento superficial da informação incomoda muito a quem está habituado a ter algum tempo para aprofundamento, tal como os professores entrevistados. Estes, conseqüentemente, não vêem com bons olhos as estratégias usadas pelos alunos, que não têm qualquer tipo de problema com a superficialidade porque nunca conheceram algo diferente. Ivone Machado, por exemplo, comenta as estratégias usadas pelos alunos:

A rapidez como eles mudam as páginas. Não deu tempo pra ler ou analisar isso aí. Daí eles dizem, ah isso não interessa. Eles até têm uns critérios deles de análise, mas tudo é muito superficial.

Muitos entrevistados sentem-se preocupados com os efeitos pedagógicos do excesso e da superficialidade da informação. Para eles, esses fenômenos estão impedindo que os alunos se tornem mais críticos, mais cuidadosos e que processem os dados de forma mais aprofundada. Como se fora porta-voz da maioria, Sueli Gomes explicita sua preocupação: 
Preocupa que o aluno é muito passivo. Ele obtém a informação, mas depois ele não quer escrever e pensar sobre aquilo. Ele só quer passar de um site para outro e entra nisso e naquilo. A minha preocupação é que isso vá deixá-los mais superficiais, sem aquele momento de reflexão.

Na opinião de Sueli e de praticamente todos os demais entrevistados, para construir conhecimento há a necessidade da intervenção dos professores; os alunos necessitam de sua ajuda durante o processamento da informação obtida. Esta tarefa, porém, não está sendo nada fácil para os educadores. Como afirma Márcia Vilella:

Eu acho que hoje em dia, até pra nós adultos, está dificil pra gente digerir a quantidade de dados que nos são dados em nosso dia a dia. Acho que eles [os alunos] estão sendo muito bombardeados. A sensação que dá, que deve ser pra eles como que aquela luz estroboscópica que está sempre piscando na frente deles. Eles não estão aparelhados para separar: isso aqui eu quero, isso aqui eu não quero.

É evidente que esses professores estão se defrontando com uma nova questão pedagógica: a de ensinar seus alunos a transformar informação em conhecimento (ou pelo menos guiá-los nessa tarefa). $\mathrm{Na}$ visão dos entrevistados, tal atuação pedagógica é particularmente necessária quando a busca e a seleção da informação acontecem na Internet. São justamente as produções dos alunos, realizadas a partir da pesquisa na rede, que fazem os entrevistados sentirem a necessidade de sua atuação. Na próxima seção será abordada com mais detalhes a atividade de pesquisa escolar usando a Internet.

\section{"Copiar-Colar": uma prática que gera polêmica}

Embora os entrevistados admitam que a Internet é um poderoso banco de dados que revolucionou a prática da pesquisa em geral, todos a vêem com reservas para a prática de pesquisas escolares. De fato, a maneira pela qual a maioria dos alunos usa a rede para suas pesquisas escolares gera polêmicas e discussões. Ângela Azevedo dá voz ao que todos os entrevistados acham, contando como muitos alunos estão procedendo:

\begin{abstract}
A Internet agora está uma febre. Todo mundo quer fazer pesquisa, ninguém quer mais ir a uma biblioteca, aliás, nem sabem o que é uma biblioteca. A Internet virou fonte de pesquisa para tudo, inclusive aposentou a vontade de ler. Porque simplesmente é mecânico, eu vou lá, clico, monto no meu computador, copio, só faço a justificação, mando imprimir e boto pro professor. Nem olham o que mandam.
\end{abstract}

A análise dos depoimentos revelou, no entanto, que há, entre os entrevistados, duas visões distintas dessa prática de "copiar-colar" e de suas implicações para o aprendizado dos alunos. Estas estão igualmente divididas entre os entrevistados.

A primeira delas é compreensiva. Os professores que expressam esta visão analisam com cuidado os comportamentos de seus alunos gerados pelas experiências na Internet, procurando não fazer julgamentos precipitados. Simone Pereira, por exemplo, entende que a cópia "não é uma desvantagem da Internet, (...) isso também acontecia com os livros". Tal como Simone, Sonia Cavalcante, procura entender o que significa aplicar o recurso do "copiar-colar" nas tarefas escolares.

\begin{abstract}
Quando eu peço uma pesquisa para os meus alunos, são sites e sites impressos que eles me trazem. É ainda a incapacidade deles de separar o que é bom e o que é ruim Isso está sendo assim um caos para os professores. Eu mesma me coloco no lugar deles. Eu vejo que você, ah, de repente posso precisar disso também, então você acaba crivando um monte de coisas e perde o cerne.
\end{abstract}

Sonia, Simone e outros professores que têm essa visão mais compreensiva da prática do "copiarcolar" utilizam os seus próprios sentimentos e sensações de usuários da rede como referência para entender o que está acontecendo com os alunos.

Já os professores que apresentam a segunda visão tendem a criticar a prática do "copiar-colar", ressaltando as conseqüências negativas de seu uso pelos alunos, além de culpabilizá-los pela prática em si. O depoimento de Aloísio Santos, entre outros, ilustra essa forma de olhar e entender essa prática:

Eu acho que ficou mais fácil a fraude. No passado eles, pelo menos, tinham que digitar real- 
mente a pesquisa. Hoje, simplesmente é control $C$, control $V$, recorte e cole, sem nenhuma cerimônia. Aí cabe ao professor criar instrumentos. Eu tenho um. Eu peço uma pesquisa na Internet, ele me traz, eu leio e devolvo pra ele com uma série de questões sobre aquilo que ele, a princípio, pesquisou. Então, para responder às questões, ele vai ter que ler. Tenta me enrolar!

Diferentemente dos professores do primeiro grupo, que procuram entender como os alunos estão vivenciando a nova realidade, os depoimentos dos professores desse segundo grupo sugerem que eles pautam seus julgamentos sobre uma realidade passada (e idealizada). Assim sendo, o "copiar-colar" é por eles visto como um novo comportamento problemático ou como um desvio. Por conseguinte, vêem como sua a tarefa de inibi-lo.

Uma convicção, porém, os dois grupos têm em comum. Ambos consideram primordial a orientação do professor para ajudar o aluno a selecionar os dados coletados na Internet com vistas à elaboração de conhecimentos.

\section{Verdades no lugar da verdade absoluta: a ins- tabilidade do conhecimento relativizado}

Vários dos nossos entrevistados afirmaram que a Internet tem possibilitado, a eles próprios e a seus alunos, o contato com visões divergentes a respeito de um mesmo assunto. "Hoje em dia, é impossível você ter uma visão unilateral”, diz Sueli Gomes.

A exposição a diferentes fontes, que veiculam conteúdos muitas vezes contraditórios, introduz um elemento bastante novo nos processos pedagógicos. Alice Duarte o identifica: "não tem mais só a opinião dos professores ou do livro dele ali do lado". Há, sim, várias opiniões disputando entre si o privilégio de serem escolhidas como verdadeiras.

A diversidade de informações e a facilidade com que a estas hoje são acessadas têm como resultado a desmistificação da concepção de verdade absoluta e a necessidade de admitir que conhecimentos são relativos e transitórios. Acostumados a se conceberem como detentores e porta-vozes de verdades confiáveis e duradouras, os entrevistados hoje se vêem obrigados a rever seu papel. O depoimento a seguir representa bem essa postura.

\begin{abstract}
Antigamente tinha lá as perguntas e o professor dava as respostas pra gente. Era ele o detentor do conhecimento. Era ali que a gente tinha contato com o conhecimento. Hoje em dia, não tem mais uma resposta. Não sou eu mais que dou. (Vera Coutinho)
\end{abstract}

No que diz respeito à qualidade da informação, a diversidade de fontes disponível na Internet é vista por todos os entrevistados como problemática. Como a rede é um espaço aberto a tudo e a todos, é possível nela encontrar não somente conteúdos de boa qualidade, mas, nas palavras de alguns, um "monte de lixo".

É como eu digo, papel aceita tudo e a Internet também. Então você tem coisas interessantíssimas, mas tem também muita porcaria, ou muita coisa superficial. Tem muita coisa errada, também. Você não pode confiar cem por cento. Eu acho que o trabalho com a enciclopédia era mais caprichoso, aquilo era mais duradouro, o virtual é mais rápido. Você bota hoje, amanhã tira, desativa, ativa de novo, lança outro texto. (Mariana de Andrade)

Como se pode observar, Mariana de Andrade adverte que a Internet não é confiável como as enciclopédias porque aceita tudo e também porque, nela, ocorre uma renovação constante das informações. Esta e outras afirmações do mesmo teor podem ser encontradas em inúmeros outros depoimentos. Em conseqüência, emergem preocupações relativas ao papel dos entrevistados como educadores. Como garantir a confiabilidade das fontes? Como identificar a fidedignidade de determinada informação? Como controlar a informação que chega aos alunos? Como ajudá-los a selecionar a informação?

Diante da dificuldade de controlar as informações veiculadas na Internet, alguns mecanismos de proteção são empregados pelos entrevistados. Orientar os alunos para que usem sites de universidades ou aqueles com terminação ponto $e d u$ é um procedimento que, a seu ver, garante alguma qualidade. Uma análise prévia pelos professores dos sites a serem utilizados ou indicados para os alunos também pode garantir a qualidade das informações. Usar referências (sites) sugeridas por fontes seguras, como, por exemplo, pelos livros didáticos, é um outro mecanis- 
mo citado. Esses mecanismos, além de facilitarem a seleção de conteúdos, parecem preservar os entrevistados de viverem situações inesperadas e desconfortáveis. Nem sempre, porém, eles são totalmente garantidos, como fica claro no depoimento abaixo:

A gente estava falando dos países que falam a língua inglesa. Os meninos acharam que para obter informações sobre os Estados Unidos seria um site chamado casabranca.com. Afinal casabranca, né? E eles estavam acostumados que era só colocar ponto com e, quando veio, era um site pornográfico. Ai foi aquela loucura! Não, não é ponto com, é ponto org. (Márcia Vilella)

A imprevisibilidade característica da rede mundial de computadores, que aparece no depoimento acima, deixa evidente que os entrevistados não podem mais controlar aquilo a que seus alunos são expostos quando estes fazem uso da Internet. E isso é, para eles, uma grande fonte de desconforto. De fato, os entrevistados demonstram estar se debatendo com a constatação inevitável de que não mais ocupam a posição privilegiada de quem transmite um saber legítimo e confiável àqueles que os têm como principal fonte de informação. Além dessas questões pedagógicas inéditas, acarretadas pela entrada da Internet no cotidiano escolar, outra, que delas decorre, será discutida a seguir: a constatação de que o conhecimento do professor tem limites que podem se tornar visíveis para os alunos.

\section{Conhecimento “intotalizável” e "indominável”: a desidealização do papel do professor}

Além das conseqüências acima discutidas, a diversidade de informações e a facilidade de acesso às mesmas desorganizam a tradicional relação professor-aluno, na qual o primeiro exercia poder sobre o segundo porque detinha o conhecimento do assunto que ensinava (conhecimento esse que, no imaginário de muitos, freqüentemente assumia proporções de um conhecimento absoluto, sem fronteiras ou qualquer tipo de relativização). Na atualidade "o conhecimento passou definitivamente para o lado do intotalizável e indominável" (Lévy, 1999 p.161).

Em seus depoimentos, os professores entrevistados revelaram ter consciência disso. Mostraram claramente haver se dado conta de que, diante da diversidade de fontes passíveis de serem consultadas nos dias de hoje e de sua constante renovação, é impossível ter a ilusão (viável em outras épocas) de dominar a totalidade do conhecimento, mesmo dentro de uma única área de saber. Em decorrência, eles se sentem vulneráveis, pois os limites do seu conhecimento podem facilmente se tornar visíveis para os alunos. Tal vulnerabilidade, antes improvável ou mesmo impensável, gera muito desconforto. Observando seus depoimentos e tenta-se compreender por que razão isso acontece.

Os depoimentos de Mara Ferreira e de Simone Pereira permitem travar contato com o conflito enfrentado pelos entrevistados. Mara diz:

Eu acho que hoje está muito complicado. $O$ professor se sente um pouco destronado. O professor ainda tem dentro dele, até como característica da nossa profissão, ele é o dono do saber.

Já Simone revela:
[Houve] uma mudança de paradigma, eu não sou mais a detentora do saber. Eu sempre tive uma postura mais aberta, mas a gente sempre tem que mudar. Foi dificil, pra mim, saber que o meu aluno sabia aquilo mais do que eu. (...) Eu não sou mais o centro da aula.

Simultaneamente, a percepção de que seu desconhecimento pode se tornar visível para seus alunos atinge diretamente a auto-estima desses educadores, na medida em que é para eles inesperado e muito difícil ter que admitir que não sabem alguma coisa. Carlos Alvarenga é um dos entrevistados que mostra claramente esse mal-estar. Diz:

Eu dou a fisica de Newton e o aluno vai entrar
na Internet e vai em Einstein. E pode ser que
Einstein eu não domine. Então fica complica-
do a gente lidar com isso. A gente vai ter que
dizer ao aluno que não dá pra explicar aquilo
pra ele e aí ele vai ficar na dúvida se não dá
pra explicar porque eu não sei ou porque ele
ainda não tem condiçóes de aprender porque
faltam pré-requisitos.

A esse mal-estar se associa outro análogo: a sensação de constante despreparo, gerada pela fre- 
qüente renovação de conteúdos, que parece se tornar fonte permanente de ansiedade. Como declara Sueli Gomes:

Dá a sensação de que você está sempre devendo. Não dá pra acompanhar a renovação dos conhecimentos. Puxa, não li ainda, não fui naquele site. Eu acho que gera uma certa ansiedade.

O que esses entrevistados parecem estar querendo dizer é que, antigamente, o professor podia ter a ilusão de dominar sua área de ensino de forma permanente. A probabilidade de ele ser confrontado com a necessidade de admitir não dominar qualquer conteúdo dentro de sua área de saber era muito pequena. O saber estava "contido" de forma estável nos livros conhecidos que adotava (livros esses que geralmente tinham uma vida longa). Além disso, era ele quem centralizava o ensino de determinada área do conhecimento: era ele quem apresentava ao aluno a matéria a ser estudada, quem dava as respostas corretas, quem comentava os textos dos livros. Hoje, porém, com o avanço das tecnologias da informação e comunicação, especialmente da Internet, o conhecimento circula, se transforma e está disponível a qualquer pessoa que tenha acesso a tais tecnologias. Como conseqüência, nesse contexto, a visão idealizada do professor como "detentor do conhecimento" não mais se sustenta.

\section{Considerações Finais} as pessoais

Desafios, soluções práticas e conseqüênci-

Tradicionalmente, ser professor tinha uma definição clara. Tanto para o público em geral quanto para os próprios docentes; ser professor consistia em deter um determinado tipo de saber e transmiti-lo. $\mathrm{O}$ advento da Internet contribuiu para colocar em xeque tal concepção de magistério e gerou nos professores a necessidade de enfrentar o penoso desafio de redefini-la.

Os resultados desta pesquisa mostram que, para começar, o acesso fácil a todo e qualquer tipo de informação disponibilizado pela Internet, além de causar preocupação, angústia e mal-estar nos docentes entrevistados (e provavelmente em muitos outros), tornou para eles imperativa uma revisão dos concei- tos de informação e conhecimento. Esta revisão, por sua vez, levou-os a se darem conta de que informação e conhecimento (que antes jamais haviam requerido reflexão aprofundada) são duas coisas muito diferentes. Como se viu nos depoimentos coletados, após hesitações e vencendo dificuldades, esses docentes revelaram ter chegado à conclusão consensual de que conhecimento é informação processada. Assim sendo, muitos passaram a ver como sua não a tarefa de transmitir informação (ou determinado tipo de saber), mas sim a de ajudar os alunos a processarem as informações que coletam de modo a transformá-las em conhecimento.

$\mathrm{Na}$ visão de muitos dos participantes da pesquisa, esta transformação de informação em conhecimento por parte dos alunos encontra um sério obstáculo na prática do copiar/colar, altamente disseminada entre eles. Esta prática causa indignação em muitos desses professores, alguns dos quais chegam a dizer categoricamente que "ficou mais fácil a fraude". Por isso, recorrem a diferentes estratégias para tentar inibi-la e obrigar os alunos a processarem os conteúdos que copiam e colam. Um bom exemplo é aquela de devolver o material, que visivelmente foi simplesmente copiado/ colado, para o aluno com questões a serem respondidas sobre o mesmo.

Os dois problemas mais sérios apontados pelos entrevistados dizem respeito, contudo, à própria concepção do que é ser professor nos dias de hoje. Ambos problemas são mais uma vez decorrentes da multiplicidade de fontes de informação.

Os conteúdos sempre renovados e muitas vezes discrepantes divulgados por essas múltiplas fontes têm inevitavelmente como resultado a desatualização e a relativização do conhecimento. Tanto a desatualização (a incapacidade de conhecer a última versão de tudo) quanto a relativização (o fato de que não há somente uma verdade) geram muita insegurança nos nossos entrevistados. Alguns chegam a revelar abertamente seu medo de serem confrontados por alguém (algum aluno) que detenha alguma informação mais nova e/ou diferente daquela que possuem. Em outras palavras, essas duas conseqüências da proliferação de informações abalam profundamente a tradicional relação professor-aluno, calcada que esta sempre esteve na concepção utópi- 
ca do professor como o detentor de um saber sem limites e como seu transmissor privilegiado. Como, nas palavras de uma entrevistada, "não há mais só a opinião dos professores", estes se sentem "destronados" da posição que sempre ocuparam na medida em que perdem o poder (de saber, de controlar, de prever) diante de seus alunos. Tal perda, como pôde ser observado em seus depoimentos, faz com que procurem redefinir sua tarefa como docentes. Como já foi visto acima, para muitos dos professores entrevistados, ao invés de transmitir conteúdos, a tarefa do professor passa a ser a de ajudar seus alunos a processarem as informações recebidas. Mas, para que isso possa ser concretizado em um ambiente em que as informações são sempre renovadas, múltiplas e muitas vezes divulgadas sem qualquer controle de qualidade, os professores se vêem no dever de ensinar os alunos a escolherem fontes confiáveis de informação - como, por exemplo, os sites.edu ou os sites indicados por livros.

A profusão de informações, a constante renovação dos conhecimentos e o fácil acesso de todos a eles têm ainda uma outra conseqüência de monta para os entrevistados. Fazem com que estes tenham que lidar com os limites do próprio conhecimento e, por vezes, tenham que, constrangidamente (porque ainda não aprenderam a lidar com o seu não-saber), admitir isso publicamente para seus alunos.

Não são poucos, portanto, os mal-estares, os conflitos, as dificuldades e tensões que os entrevistados estão experimentando na aplicação da Internet em seu cotidiano. É preciso, no entanto, registrar que, como seus depoimentos tornam evidente, embora a Internet pareça representar uma fonte inesgotável de problemas e sofrimentos pessoais para esses docentes, eles próprios já sentiram a necessidade de aceitar os vários desafios envolvidos na redefinição de uma atividade tão tradicional quanto o magistério.

\section{Referências}

Araújo, R. B.; Battaiola, A. L. \& Goyos, C. (1997). Exploração do Uso de Realidade Virtual no Aprendizado de Habilidades Acadêmicas para o Ensino Fundamental. Revista Brasileira de Informática na Educação (RBIE),. Disponível em <http:// www.sbc.org.br $>$ Acesso em 20 abr. 2001
Boettcher, D. (2005). A Internet como dispositivo potencializador didático. Em N. M. C. Pellanda, E. T. M. Schlünzen \& K. S. Junior, (Orgs.), Inclusão Digital: tecendo redes afetivas/cognitivas (pp. 45-60). Rio de Janeiro: DP\&A.

Candeias, C. N. B. (1998). Significado do Trabalho e as Novas tecnologias: uma visão a partir do trabalho docente. Dissertação de Mestrado em Educação - Faculdade de Educação, Universidade Federal da Bahia.

Castells, M. (1999). A Sociedade em Rede. São Paulo: Paz e Terra

Cebrián, J. L. (1999). A Rede: como nossas vidas serão transformadas pelos novos meios de comunicação. São Paulo: Summus Editorial.

Dertouzos, M. (1997). O que será: como o novo mundo da informação transformará nossas vidas. São Paulo: Companhia das Letras.

Lévy, P. (1999). Cibercultura. Rio de Janeiro: Editora 34.

Lojkine, J. (1995). A Revolução Informacional. São Paulo: Cortez.

Lucena, C. \& Fuks, H. (2000). Professores e aprendizes na Web: a educação na era da Internet. Rio de Janeiro: Clube do Futuro.

Maçada, D. L., Sato, L. S. \& Maraschin, C. (2001). Educação sem Distâncias: uma experiência de convivência em ambiente digital de aprendizagem. Revista Brasileira de Informática na Educação, n. 9, p. 27-34.

Magdalena, B. C. \& Costa, I. E. T. (2003). Internet em Sala de Aula: com a palavra, os professores. Porto Alegre: Artmed.

Negroponte, N. (1995). Vida Digital. São Paulo: Companhia das Letras

Nicolaci-Da-Costa, A. M. (1987). Sujeito e cotidiano: um estudo da dimensão psicológica do social. Rio de Janeiro: Campus

Nicolaci-Da-Costa, A. M. (1994). A análise de discurso em questão. Psicologia: Teoria e Pesqui$s a$, v.10, n.2, p.317-331. 
Nicolaci-Da-Costa, A. M. (2002). Revoluções tecnológicas e transformações subjetivas. Psicologia: Teoria e Pesquisa, v.18, n.2, p.193-202.

Nicolaci-Da-Costa, A. M. (no prelo). O campo da pesquisa qualitativa e o Método de Explicitação do Discurso Subjacente (MEDS). Psicologia: Reflexão e Crítica.

Ramal, A. C. (2002). Educação na Cibercultura: hipertextualidade, leitura, escrita e aprendizagem, Porto Alegre: Artmed.

Suguri, V.; Matos, L.; Castro, N.; Castro, I.; Jung, L. M. \& Rusten, E.(2002). O Uso Pedagógico do Web-Based-Chat: uma atividade piloto para explorar o potencial pedagógico do web-based-chat. Disponível em $<$ http://www.proinfo.gov.br. $>$ Acesso em 15 março 2002.

O presente artigo é derivado da tese de doutorado intitulada "A Internet na prática docente: novos desafios e conflitos para os educadores", orientada pela segunda autora e defendida pela primeira no Departamento de Psicologia da PUC-Rio. 